\title{
Effect of a small dose of propofol or ketamine to prevent coughing and laryngospasm in children awakening from general anesthesia
}

\author{
Hae Jin Pak, Won Hyung Lee, Sung Mi Ji, and Youn Hee Choi \\ Department of Anesthesiology and Pain Medicine, Chungnam National University School of Medicine, Daejeon, Korea
}

Background: Coughing during emergence from general anesthesia may be detrimental in children. We compared the effect of a small dose of propofol or ketamine administered at the end of sevoflurane anesthesia on the incidence or severity of coughing in children undergoing a minimal invasive operation.

Methods: One hundred and eighteen children aged between 3 and 15 years, American Society of Anesthesiologists (ASA) status I, were enrolled in this randomized double blind study. Anesthesia was induced with propofol or ketamine and maintained with sevoflurane in $\mathrm{N}_{2} \mathrm{O} / \mathrm{O}_{2}$. Each group received propofol $0.25 \mathrm{mg} / \mathrm{kg}$ or ketamine 0.25 $\mathrm{mg} / \mathrm{kg}$ and the control group received saline $0.1 \mathrm{ml} / \mathrm{kg}$. The decision to perform tracheal extubation was based on specified criteria, including the resumption of spontaneous respiration. During emergence from anesthesia and extubation, coughing was observed and graded at predefined times.

Results: The incidence of emergence without coughing was higher in the propofol group than in the ketamine and control group (19\%, 11\% and 6\%, respectively), whereas the incidence of severe coughing was higher in the control group than in propofol and ketamine group $(17.14 \%, 10.0 \%$ and $6.98 \%$, respectively).

Conclusions: The addition of propofol $0.25 \mathrm{mg} / \mathrm{kg}$ decreased the incidence of coughing after sevoflurane general anesthesia in children undergoing non-painful procedures. (Korean J Anesthesiol 2011; 60: 25-29)

Key Words: Cough, Ketamine, Propofol.

Received: June 29, 2010. Revised: 1st, July 25, 2010; 2nd, August 18, 2010. Accepted: August 19, 2010.

Corresponding author: Won Hyung Lee, M.D., Ph.D., Department of Anesthesiology and Pain Medicine, Chungnam National University School of Medicine, Daesa-dong, Jung-gu, Daejeon 301-721, Korea. Tel: 82-42-280-7840, Fax: 82-42-280-7968, E-mail: whlee@cnu.ac.kr

(c) This is an open-access article distributed under the terms of the Creative Commons Attribution Non-Commercial License (http:// creativecommons.org/licenses/by-nc/3.0/), which permits unrestricted non-commercial use, distribution, and reproduction in any medium, provided the original work is properly cited. 


\section{Introduction}

During emergence from general anesthesia, airway irritation at extubation causes coughing which often causes serious sideeffects, but coughing is accepted as a biological response that protects the airway from aspiration [1]. However, coughing not only causes heavy discomfort to the patient, but also causes hypertension and palpitation, elevates intracranial pressure, intraocular pressure, and abdominal pressure, and causes coronary ischemia and arrhythmia [2-5]. Airway irritation causing coughing in pediatric patients can also cause lifethreatening laryngospasm [6].

There has been considerable research conducted on methods and drugs to prevent coughing during emergence such as extubation at a great anesthetic depth [7], the use of LMA [8], the administration of IV lidocaine [9], short-acting opioids [10,11], dexmedetomidine [12], and lidocaine by local administration [13] or by cuff [14]. These methods all come with advantages and disadvantages.

Propofol at the anesthetic dose is known to strongly suppress airway responses $[15,16]$. At a lower concentration than the anesthetic dose, propofol is known to prevent laryngospasm during extubation in pediatric patients [17]. Ketamine, due to its effects on sympathetic treacheal dilatory effect, is considered an attractive intravenous anesthetic for asthmatic patients needing anesthesia and intubation for recovery from asthmatic symptoms [18].

However, the effects of propofol and ketamine in preventing coughing during emergence have not been analyzed in pediatric patients until now. Therefore, we have performed this study in order to analyze the effects of a low dose of propofol or ketamine on laryngospasm and the cough response during the emergence from anesthesia.

\section{Materials and Methods}

After receiving approval for the present study from the ethics committee of the hospital, the anesthesia and study methods were explained to the guardian of patients. The study proceeded

Table 1. Patient Characteristics for the Different Groups

\begin{tabular}{lccc}
\hline & $\begin{array}{c}\text { Propofol } \\
\text { group } \\
(\mathrm{n}=40)\end{array}$ & $\begin{array}{c}\text { Ketamine } \\
\text { group } \\
(\mathrm{n}=43)\end{array}$ & $\begin{array}{c}\text { Control } \\
\text { group } \\
(\mathrm{n}=35)\end{array}$ \\
\hline Age (yr) & $6.8 \pm 3.2$ & $8.6 \pm 2.2$ & $8.1 \pm 2.7$ \\
Weight (kg) & $26.1 \pm 14.9$ & $33.6 \pm 8.0$ & $31.5 \pm 10.6$ \\
Height (cm) & $122.2 \pm 19.2$ & $131.4 \pm 14.6$ & $130.9 \pm 14.1$ \\
Gender (male/female) & $26 / 17$ & $23 / 17$ & $22 / 13$ \\
Operation time (min) & $43.6 \pm 22.2$ & $45 \pm 20.1$ & $56.1 \pm 20.9$ \\
\hline
\end{tabular}

Values are mean \pm SD or number of patients. upon receiving the written consent from the guardian of patients participating in the study. 118 ASA I patients of 3-15 years who were scheduled for noninvasive surgery under general anesthesia such as strabismus correction and indirect hernia repair were chosen for the study. Patients were excluded from the study if they had a past history of sleep apnea syndrome, developmental disorder, airway or facial abnormalities, bronchial asthma, an allergic disorder, or if they had an upper respiratory infection symptom during the surgery (Table 1).

All patients were NPO. As pre-anesthetic medication, glycopyrrolate $0.004 \mathrm{mg} / \mathrm{kg}$ was IM administrated $30 \mathrm{~min}$ before surgery. On the OR table, noninvasive monitoring of blood pressure, EKG, and pulse oxymetry were initiated. Anesthetic induction was done by IV administration of ketamine $1.5 \mathrm{mg} / \mathrm{kg}$ or propofol $2 \mathrm{mg} / \mathrm{kg}$. At the loss of consciousness, rocuronium $0.8 \mathrm{mg} / \mathrm{kg}$ was IV administered and intubation was performed. Anesthetic maintenance was performed by $\mathrm{O}_{2}$ and $\mathrm{N}_{2} \mathrm{O}$ each at $1.5 \mathrm{~L} / \mathrm{min}$, sevoflurane was administered at $2.0-2.5 \mathrm{vol} \%$, and controlled respiration was performed with capnogram maintained at $30-35 \mathrm{mmHg}$.

At the end of the surgery, the level of muscle relaxation was evaluated by the use of Train-of-four. If three or more twitches occurred, then the residual muscle relaxants, pyridostigmine $0.2 \mathrm{mg} / \mathrm{kg}$ and glycopyrolate $0.01 \mathrm{mg} / \mathrm{kg}$ were IV administered. Afterwards, sevoflurane and $\mathrm{N}_{2} \mathrm{O}$ were turned off, and manual ventilation was performed by $\mathrm{O}_{2}$ at $4 \mathrm{~L} / \mathrm{min}$. A doctor blind to the anesthesia study placed the test patients randomly in the control group, the propofol group, and the ketamine group. Normal saline $0.1 \mathrm{ml} / \mathrm{kg}$ was IV administered in the control group, propofol $0.25 \mathrm{mg} / \mathrm{kg}$ in the propofol group, and ketamine $0.25 \mathrm{mg} / \mathrm{kg}$ in the ketamine group. The anesthesiologist gave the patients the drugs prepared by the blinded doctor. The administration time of the drugs given on emergence were defined in the study by Batra et al. [17], which were either when the pediatric patient's breathing pattern returned to normal, or when the patient opened their eyes or made concentrated movement such as trying to remove the endotracheal tube with his hands. One min after administering the drugs respective of the groups, the endotracheal secretion was aspired and removed, and following that, the patient was extubated.

After extubation, when the return of normal breathing was confirmed, the patient was moved to the PACU. During this process, laryngospasm and cough responses within 2 minutes after extubation were recorded based on the on the study by Batra et al. [17]. When there were no symptoms, grade 0 was given. When a stridor was heard, grade 1 was given. When there was spontaneous respiratory effort but suspicion of complete stenosis in the trachea, grade 2 was given. When $\mathrm{SpO}_{2}$ was $85 \%$ or below or when cyanosis was observed due to airway obstruction, grade 3 was given. The severity of coughing was 
determined by using the graded categorizations of Minogue et al. [13]. After extubation, no incidence of coughing was given grade 0 , only one cough was given grade 1 , two coughs to slight coughing was grade 2 , and severe or repetitive coughing was given grade 3 .

With laryngospasm after extubation, positive pressure ventilation was performed by a face mask with $100 \%$ oxygen. If no recovery occurred, the laryngospasm continued, and $\mathrm{SpO}_{2}$ dropped to $85 \%$ or below, a small dose of propofol $(0.8 \mathrm{mg} /$ $\mathrm{kg}$ ) was administered and positive pressure ventilation was maintained. If laryngospasm persisted, succinylcholine was administered, the patient was intubated, and then ventilated with $100 \%$ oxygen in the study.

After assessing the cough responses and laryngospasm on emergence, the recovery status was recorded twice by a nurse blinded to the experiment, once upon the patient arriving into PACU, and $30 \mathrm{~min}$ later in the PACU based on the recovery score (Table 2).

The scores were shown as mean \pm SD or in percentages. SPSS software version 17.0 ( SPSS Inc., Chicago, IL, USA) was used. Score ratios were assessed by Pearson's $\chi^{2}$ test, and continuous variables were assessed by a two-tailed unpaired t-test. The $\mathrm{P}$ value was considered statistically significant if below 0.05 .

\section{Results}

There were no significant differences observed in the child patient's age, weight, height, gender, and operation time (Table 1). Fig. 1 shows the severity of coughing, the absolute scores, and relative rates of each group. The control group had $17.14 \%$ cases of severe coughing given grade 3 . This was considerably higher than the propofol group which had $10 \%$ and the ketamine group which had $6.98 \%$. For no coughing (grade 0 ), the control group

Table 2. Recovery Scores

\begin{tabular}{llll}
\hline \multicolumn{1}{c}{0} & \multicolumn{1}{c}{1} & \multicolumn{1}{c}{2} \\
\hline Activity & None & Depression & Normal \\
Respiration & None & Depression & Normal \\
Circulation & $\pm 50 \%$ of preop. & $\pm 20 \%$ of preop. & $\pm 10 \%$ of preop. \\
Consciousness & No response & Not accurate & Accurate \\
Color & Cyanosis & Mild change & Normal \\
\hline
\end{tabular}

Preop.: preoperative values.

Table 3. Result of Recovery Score

\begin{tabular}{lll}
\hline \multicolumn{1}{c}{ Group } & At arrival & $30 \mathrm{~min}$ \\
\hline Propofol & $8.90 \pm 0.71$ & $9.45 \pm 0.71$ \\
Ketamine & $8.84 \pm 0.79$ & $9.72 \pm 0.50$ \\
Control & $8.77 \pm 0.77$ & $9.43 \pm 0.74$ \\
\hline
\end{tabular}

Values are mean \pm SD or number of patients. P value is greater than 0.05 . had $6 \%$, whereas the ketamine group had $11 \%$ and the propofol group had $19 \%$. Pearson's $\chi^{2}$ test on the propofol group and the control group showed a significant difference of $\mathrm{P}=0.047$, but the test on the ketamine group and the control group showed no significant difference of $\mathrm{P}>0.05$.

Also on laryngospasm, all patients in the propofol group and the ketamine group received grade 0 . There were 3 cases of grade 1 only in the control group, but there was no statistical significance $(\mathrm{P}>0.05)$. There were no significant differences in the recovery scores in the PACU (Table 3$)(\mathrm{P}>0.05)$. There were no significant differences $(\mathrm{P}>0.05)$ in the types of surgeries (Table 4).

\section{Discussion}

Although in the past there has been research on the suppression of laryngospasm in children by the administration of small doses of propofol [19], there were no reports on

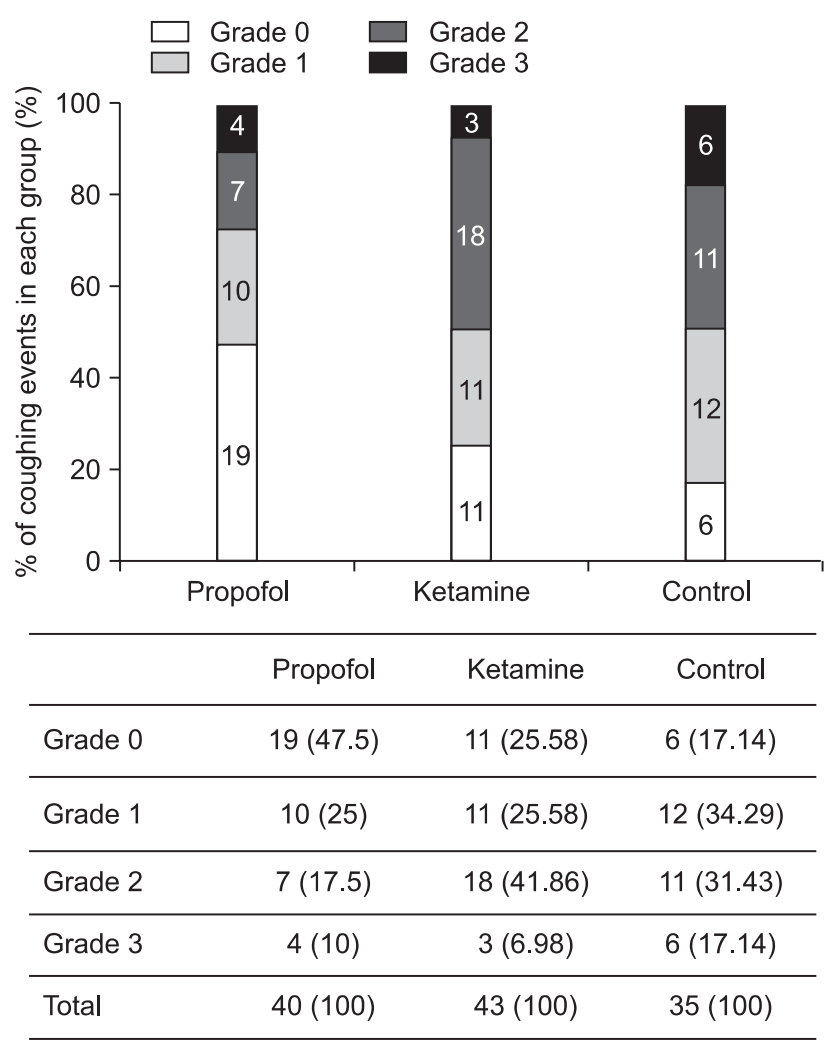

Fig. 1. Occurrence of cough (Grades $0-3$ ) and the percentage of coughing events recorded in each group (propofol, ketamine, control). The table provides the absolute recorded numbers and proportions [n=number of Grades $0,1,2$, or 3 coughing events recorded, irrespective of the time point of interest (\%, proportion of the total number of coughing events in the group)]. Grade 0 , no cough; Grade 1, mild cough; Grade 2, moderate cough; Grade 3, severe cough. Propofol vs control $(\mathrm{P}=0.047)$. Ketamine vs control ( $\mathrm{P}$ $>0.05$ ) by Pearson $\chi^{2}$ tests. 
Table 4. Types of Operations by Group

\begin{tabular}{lccc}
\hline & Propofol & Ketamine & Control \\
\hline Tonsillectomy \& adenoidectomy & 11 & 10 & 10 \\
Periauricular fistulectomy & 1 & 2 & 0 \\
Herniorrhaphy & 12 & 14 & 12 \\
Sistrunk operation & 2 & 1 & 1 \\
Chemoport operation & 3 & 2 & 1 \\
Periorbital muscle recession & 10 & 13 & 10 \\
Silicon oilremoval & 2 & 1 & 2 \\
Total & 40 & 43 & 35 \\
\hline
\end{tabular}

$P$ value is greater than 0.05 .

cough responses. Despite ketamine being used as an efficient tracheal dilator, there has been no research on the effect of its concentration dose below anesthetic dose on emergence. We learned from the presented research results that a low dose of propofol after sevoflurane $/ \mathrm{N}_{2} \mathrm{O}$ anesthesia reduces coughing on emergence in children.

Reports that used less propofol than the anesthetic dose generally used $0.8 \mathrm{mg} / \mathrm{kg}$ [19] or $0.5 \mathrm{mg} / \mathrm{kg}$ for the prevention of laryngospasm [17]. Ketamine $0.75 \mathrm{mg} / \mathrm{kg}$ was used in asthmatic patients to set back laryngospasm [20]. However, there have been no studies focused on reducing coughing on emergence from anesthesia. Also there have been no quantitative comparative studies between propofol and ketamine. Therefore, in the presented study we used an equal amount of propofol and ketamine, less than the doses used in research on laryngospasm and bronchospasm. In conclusion, propofol of $0.25 \mathrm{mg} / \mathrm{kg}$ showed a statistically significant ability to suppress coughing. In the present study, to compare propofol and ketamine, the same doses were used to not eliminate the possibility of significant results from the use of higher doses of ketamine. However, it must be considered that ketamine may raise endotracheal secretion, which has a negative effect on extubation.

There have been various reported frequencies of coughing on emergence from anesthesia. It is reported that they occur in 96\% patients after extubation [21]. Also, such cough responses occur from the chemically or mechanically sensitive ascending vagus nerve [22]. However, cough responses are also effected by other ascending nerves and organs, the thorax, the diaphragm, and nerves connected to the abdominal muscles [23]. It is not clear whether propofol can specifically suppress responses to airway irritation, yet there has been a report that it might be due to the diminishing effect of propofol on laryngeal responses [15]. Also, propofol is considered to effectively suppress N-methyl-Daspartate (NMDA) receptors and block the ascending pathway from the trachea [24]. Ketamine is known for its mechanism of suppressing NMDA receptors which effectively suppresses coughing [25]. In addition, ketamine relaxes the bronchiole muscle, suppresses the bronchus from constricting due to histamines, and reduces the possibility of tracheal spasms [26]. Such effects result not only from the build-up of catecholamines but also from the direct effect on the bronchial muscles [26].

The frequencies of laryngospasm on emergence from anesthesia in children are reported to be $0.9 \%$ at the lowest and $21-26 \%$ at the highest in certain surgeries such as tonsilectomy $[17,27-30]$. In the present study, there were $8.6 \%$ laryngospasmrelated responses in the control group, but there were no cases observed in the propofol or ketamine groups.

In summary, even a small dose of propofol $0.25 \mathrm{mg} / \mathrm{kg}$ on emergence from anesthesia has a significant suppressant effect. However, additional studies are required on quantified doses of propofol on the effect of cough responses on the emergence from anesthesia. Also in the present study, ketamine was used in surgeries such as tonsillectomy which is known to raise the frequency of laryngospasm, but nevertheless showed lower results than the known frequencies. This is most likely due to the effects of propofol and ketamine used in anesthetic induction. This assumption requires further comparative research with greater sample sizes.

\section{References}

1. Kim ES, Bishop MJ. Cough during emergence from isoflurane anesthesia. Anesth Analg 1998; 87: 1170-4.

2. Irwin RS. Complications of cough: ACCP evidence-based clinical practice guidelines. Chest 2006; 129: 54S-8S.

3. Leech P, Barker J, Fitch W. Proceedings: changes in intracranial pressure and systemic arterial pressure during the termination of anaesthesia. Br J Anaesth 1974; 46: 315-6.

4. Holden R, Morsman CD, Butler J, Clark GS, Hughes DS, Bacon PJ. Intra-ocular pressure changes using the laryngeal mask airway and tracheal tube. Anaesthesia 1991; 46: 922-4.

5. Bidwai AV, Bidwai VA, Rogers CR, Stanley TH. Blood-pressure and pulse-rate responses to endotracheal extubation with and without prior injection of lidocaine. Anesthesiology 1979; 51: 171-3.

6. Alalami AA, Ayoub CM, Baraka AS. Laryngospasm: review of different prevention and treatment modalities. Paediatr Anaesth 2008; 18: 281-8.

7. Neelakanta G, Miller J. Minimum alveolar concentration of isoflurane for tracheal extubation in deeply anesthetized children. Anesthesiology 1994; 80: 811-3.

8. Koga K, Asai T, Vaughan RS, Latto IP. Respiratory complications associated with tracheal extubation. Timing of tracheal extubation and use of the laryngeal mask during emergence from anaesthesia. Anaesthesia 1998; 53: 540-4.

9. Saghaei M, Reisinejad A, Soltani H. Prophylactic versus therapeutic administration of intravenous lidocaine for suppression of postextubation cough following cataract surgery: a randomized double blind placebo controlled clinical trial. Acta Anaesthesiol Taiwan 2005; 43: 205-9.

10. Mendel P, Fredman B, White PF. Alfentanil suppresses coughing 
and agitation during emergence from isoflurane anesthesia. J Clin Anesth 1995; 7: 114-8.

11. Shajar MA, Thompson JP, Hall AP, Leslie NA, Fox AJ. Effect of a remifentanil bolus dose on the cardiovascular response to emergence from anaesthesia and tracheal extubation. Br J Anaesth 1999; 83: 654-6.

12. Guler G, Akin A, Tosun Z, Eskitascoglu E, Mizrak A, Boyaci A. Single-dose dexmedetomidine attenuates airway and circulatory reflexes during extubation. Acta Anaesthesiol Scand 2005; 49: 108891.

13. Minogue SC, Ralph J, Lampa MJ. Laryngotracheal topicalization with lidocaine before intubation decreases the incidence of coughing on emergence from general anesthesia. Anesth Analg 2004; 99: 1253-7.

14. Fagan C, Frizelle HP, Laffey J, Hannon V, Carey M. The effects of intracuff lidocaine on endotracheal-tube-induced emergence phenomena after general anesthesia. Anesth Analg 2000; 91: 201-5.

15. McKeating K, Bali IM, Dundee JW. The effects of thiopentone and propofol on upper airway integrity. Anaesthesia 1988; 43: 638-40.

16. Sundman E, Witt H, Sandin R, Kuylenstierna R, Bodén K, Ekberg O, et al. Pharyngeal function and airway protection during subhypnotic concentrations of propofol, isoflurane, and sevoflurane: volunteers examined by pharyngeal videoradiography and simultaneous manometry. Anesthesiology 2001; 95: 1125-32.

17. Batra YK, Ivanova M, Ali SS, Shamsah M, Al Qattan AR, Belani KG. The efficacy of a subhypnotic dose of propofol in preventing laryngospasm following tonsillectomy and adenoidectomy in children. Paediatr Anaesth 2005; 15: 1094-7.

18. Brown RH, Wagner EM. Mechanisms of bronchoprotection by anesthetic induction agents: propofol versus ketamine. Anesthesiology 1999; 90: 822-8.

19. Afshan G, Chohan U, Qamar-Ul-Hoda M, Kamal RS. Is there a role of a small dose of propofol in the treatment of laryngeal spasm?
Paediatr Anaesth 2002; 12: 625-8.

20. Sarma VJ. Use of ketamine in acute severe asthma. Acta Anaesthesiol Scand 1992; 36: 106-7.

21. Estebe JP, Dollo G, Le Corre P, Le Naoures A, Chevanne F, Le Verge $\mathrm{R}$, et al. Alkalinization of intracuff lidocaine improves endotracheal tube-induced emergence phenomena. Anesth Analg 2002; 94: 22730 .

22. Widdicombe JG. Afferent receptors in the airways and cough. Respir Physiol 1998; 114: 5-15.

23. Sant'Ambrogio G. Afferent pathways for the cough reflex. Bull Eur Physiopathol Respir 1987; 23 Suppl 10: 19s-23s.

24. Orser BA, Bertlik M, Wang LY, MacDonald JF. Inhibition by propofol (2,6 di-isopropylphenol) of the N-methyl-D-aspartate subtype of glutamate receptor in cultured hippocampal neurones. Br J Pharmacol 1995; 116: 1761-8.

25. Church J, Jones MG, Davies SN, Lodge D. Antitussive agents as N-methylaspartate antagonists: further studies. Can J Physiol Pharmacol 1989; 67: 561-7.

26. Burburan SM, Xisto DG, Rocco PR. Anaesthetic management in asthma. Minerva Anestesiol 2007; 73: 357-65.

27. Olsson GL, Hallen B. Laryngospasm during anaesthesia. A computer-aided incidence study in 136,929 patients. Acta Anaesthesiol Scand 1984; 28: 567-75.

28. Leicht P, Wisborg T, Chraemmer-Jørgensen B. Does intravenous lidocaine prevent laryngospasm after extubation in children? Anesth Analg 1985; 64: 1193-6.

29. Koç C, Kocaman F, Aygenç E, Ozdem C, Cekiç A. The use of preoperative lidocaine to prevent stridor and laryngospasm after tonsillectomy and adenoidectomy. Otolaryngol Head Neck Surg 1998; 118: 880-2.

30. Lee CK, Chien TJ, Hsu JC, Yang CY, Hsiao JM, Huang YR, et al. The effect of acupuncture on the incidence of postextubation laryngospasm in children. Anaesthesia 1998; 53: 917-20. 